\title{
$\mathbf{R}$
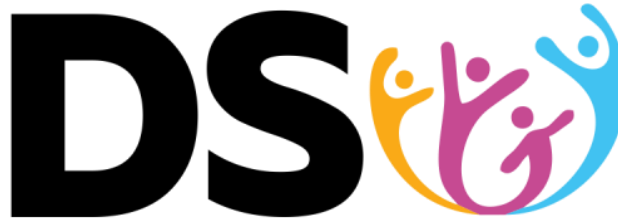

Vol. 27, n. 2, jul/dez, 2021

Revista Desenvolvimento Social

ISSN: 2179-6807 (online)

\section{A CAMPANHA DE ALFABETIZAÇÃO EM CUBA, PAULO FREIRE, EDUCAÇÃO POPULAR, E A CAMPANHA DE PÉ NO CHÃO TAMBÉM SE APRENDER A LER}

Heiberle Hirsgberg Horácio ${ }^{1}$

Recebido em: $13 / 10 / 2021$

Aprovado em: 20/12/2021

Resumo: Este artigo traz apontamentos relacionados à conjuntura e à organização da Campanha de Alfabetização de Cuba (1961), e da Campanha de Alfabetização "De Pé no Chão também se aprende a ler" (1961-1964), além de apontamentos sobre como o "método" do educador Paulo Freire esteve presente na segunda, que se caracteriza por ter sido uma experiência peculiar de Educação Popular. $\mathrm{O}$ artigo objetiva que os apontamentos possam possibilitar reflexões sobre os processos organizativos das duas Campanhas, e sobre a conjuntura e o contexto do surgimento delas, sendo que, se houve uma relação de influência da experiência cubana à experiência brasileira, a primeira foi plenamente desenvolvida, enquanto a segunda foi interrompida, mas não definitivamente silenciada, pelo Golpe Civil-Militar de 1964 e pela Ditadura Militar. Ditadura que, inclusive, levou à prisão e ao exílio Paulo Freire, Djalma Maranhão, e Moacyr de Góes, entre outras pessoas, que foram imprescindíveis para o desenvolvimento da Campanha "De Pé no Chão também se aprende a ler", tendo sido Góes, inclusive, coordenador da Campanha.

Palavras-chave: Alfabetização. Cuba. Freire. Educação Popular. "De Pé no Chão".

\section{THE LITERACY CAMPAIGN IN CUBA, PAULO FREIRE, POPULAR EDUCATION, AND CAMPAIGN DE PÉ NO CHÃO TAMBÉM SE APRENDE A LER}

Abstract: This article brings notes related to the situation and organization of the Literacy Campaign in Cuba (1961), and the Literacy Campaign "De Pé no Chão também se aprende a ler"

\footnotetext{
${ }^{1}$ Realizou Pós-Doutorado em Ciências Sociais (UFJF). Doutor e Mestre em Ciência da Religião, área Ciências Sociais da Rel. (UFJF). Graduado em Filosofia (UFSJ) e graduação em História. Realizou Especialização em Filosofia (UFOP); em Planejamento, Gestão e Implementação em EAD (UFF); e em TV, Cinema e Mídias Digitais (UFJF). Professor do Programa de Pós Graduação em Educação; Prof. Efetivo do Depto de Filosofia e do curso de Ciências da Religião - Unimontes. Coordena o GDECO-ETNOPO - Grupo de Pesquisa para uma Educação Decolonial PluriEtnoPopular. Coordenou a Licenciatura em Ciências da Religião de 2016 até 2020, na Unimontes. Coordenou o PIBID de Ciências da Religião e de Filosofia, de 2016 até 2020. GRANDES ÁREAS DE ATUAÇÃO: a) Pedagogias Decoloniais, Educação Popular, Regimes de Conhecimento Indígena e a lei 11645/08; b) Filosofia Política, Religião e Política; d) Ciências da Religião e Antropologia da Religião. Integrante do GEIPI-ABA - Grupo de Estudos Interdisciplinares com Povos Indígenas da Unimontes; Líder do Grupo de Pesquisa Religiões e Religiosidades Ameríndias - UFJF e Unimontes; Integrante do Projeto de Extensão Cursinho Popular Darcy Ribeiro, e integrante do (IN)Serto: Núcleo pela Diversidade Sexual e de Gênero da Unimontes. E-mail: heiberle@hotmail.com - ORCID: https://orcid.org/0000-0002-4486-1764.
} 
(1961-1964), as well as notes on how the "method" of the educator Paulo Freire was present at the second, which stands out for having been a peculiar experience of Popular Education. The article aims that the notes can enable reflections on the organizational processes of the two Campaigns, and on the situation and context of their emergence, if there was a relationship of influence from the Cuban experience to the Brazilian experience, the first was fully developed, while the second was interrupted, but not definitively silenced, by the Civil-Military Coup of 1964 and by the Military Dictatorship. Dictatorship that even led to prison and exile Paulo Freire, Djalma Maranhão, and Moacyr de Góes, among others, who were essential for the development of the Campaign "De Pé no Chão também se aprende a ler", the Campaign even having Góes as its coordinatinator.

Keywords: Literacy. Cuba. Paulo Freire. Popular Education. "De Pé no Chão".

\section{LA CAMPAÑA DE ALFABETIZACIÓN EN CUBA, PAULO FREIRE, EDUCACIÓN POPULAR Y LA CAMPAÑA DE PÉ NO CHÃO APRENDE TAMBÉM SE APRENDER A LER}

Resumen: Este artículo presenta notas relacionadas con la situación y organización de la Campaña de Alfabetización en Cuba (1961) y la Campaña de Alfabetización "De Pé no Chão também se aprende a ler" (1961-1964) en Brasil, además de apuntes sobre cómo el "método" del educador Paulo Freire estuvo presente en el método brasileño, que se caracteriza por haber sido una experiencia peculiar de Educación Popular. El artículo pretende posibilitar las notas para reflexionar sobre los procesos organizativos de las dos Campañas, y sobre la situación y contexto de su surgimiento, considerando si existió una relación de influencia entre la experiencia cubana y la experiencia brasileña. El primero se desarrolló plenamente, mientras que el segundo fue interrumpido, pero no silenciado definitivamente, por el Golpe Cívico-Militar de 1964 y por la Dictadura Militar. Dictadura que incluso llevó a prisión y exilio a Paulo Freire, Djalma Maranhão, Moacyr de Góes, entre otras personas que fueron fundamentales para el desarrollo de la Campaña "De Pé no Chão también aprende a leer", habiendo sido Góes, incluido, coordinador de Campaña.

Palabras-clave: Alfabetización. Cuba. Freire. Educación Popular. "De Pé no Chão".

\section{INTRODUÇÃO}

Significativas foram as campanhas e ações de alfabetização de adultos e adultas na década de 60 no Brasil, bem como os movimentos de Educação Popular, sendo que, segundo Moacyr de Góes, coordenador da campanha de alfabetização “De Pé no Chão também se aprender a ler", a Educação Popular possui proposta "indissoluvelmente ligada ao nome de Paulo Freire", e em "sua certidão de batismo consta como local de nascimento a cidade do Recife (PE) e como data a de maio de 1960" (2002), se referindo Góes à fundação do MCP - Movimento de Cultura Popular.

Em que pese a importância das campanhas anteriores à década de 1960, como a CNAA - Campanha Nacional de Educação de Adolescentes e Adultos, criada pelo Ministério da Educação em Saúde e iniciada em 1947, a CNER - Campanha Nacional de 
Educação Rural, de decreto de 1956, e o SIRENA - Sistema Rádio Educativo Nacional, criado em 1957, será a partir do final da década de 50 e início da década de 1960 que diferentes propostas e movimentos de alfabetização de adultos e adultas ganharão mais força, não só em razão do decreto federal 51.522 de 1961 que instituiu a Mobilização Nacional contra o Analfabetismo, mas, também, por causa de uma conjuntura que tem a Revolução Cubana de 1959; o Concílio Vaticano II em 1961 - e suas consequências futuras, como a Teologia da Libertação e a Conferência de Medellín -; a entrada no governo do presidente João Goulart, além de mandatos de importantes lideranças políticas, como o do prefeito Djalma Maranhão, em Natal, e o do prefeito Miguel Arraes, em Recife; o surgimento das Ligas Camponesas de Francisco Julião em 1958; as discussões relacionadas à LDB de 1961; a construção, pela CNBB, do MEB - Movimento de Educação de Base, em 1961; o CPC- Centro Popular de Cultura, criado pela UNE em 1961, entre outras.

Portanto, a conjuntura, as dinâmicas, fatos e movimentos supracitados, do final da década de 1950 e início da de 1960, contribuíram para o desenvolvimento, de maneira mais aguda, de algumas campanhas, tendo surgido nesse contexto não só o “MCP- Movimento de Cultura Popular de Recife" - ele mesmo ampliado depois para outras cidades de Pernambuco -, mas, também a "CEPLAR - Campanha de Educação Popular da Paraíba", em 1962; a experiência em Angicos, no Rio Grande do Norte, com o método do educador Paulo Freire, e, ainda, a Campanha "De Pé no chão também se aprender a ler", em Natal, com o prefeito Djalma Maranhão, e com o Secretário de Educação de Natal, Moacyr de Góes.

A Campanha "De Pé no Chão Também se Aprende a Ler" assim como as outras campanhas e ações foram, de alguma forma, sintetizadas no Plano Nacional de Alfabetização, triste e violentamente interrompido pelo Golpe Civil-Militar de 1964.

Em que pese a imprescindibilidade de reflexões, registros e diálogos sobre o Plano Nacional de Alfabetização, mas considerando também que, devido à conjuntura, acontecia em Cuba uma Campanha de Alfabetização praticamente no mesmo momento das campanhas de alfabetização que estavam em desenvolvimento no Brasil, este artigo procurará trazer apontamentos relacionados à experiência cubana e à experiência brasileira "De Pé no Chão também se aprende a ler", apontamentos que poderão possibilitar reflexões sobre os processos organizativos das duas Campanhas, e sobre a 
conjuntura do surgimento delas, conjuntura que teve a realização exitosa da primeira, e a interrupção violenta da segunda pelo Golpe Civil-Militar, e pela Ditadura Militar advinda dele. Ditadura que, inclusive, levou à prisão e ao exílio Paulo Freire e Djalma Maranhão, que foram importantíssimos para o desenvolvimento da Campanha "De Pé no Chão também se aprende a ler", que por sua vez também teve influência da Campanha de Alfabetização de Cuba.

\section{A CAMPANHA DE ALFABETIZAÇÃO EM CUBA}

A Campanha de Alfabetização se inseriu "dentro da ampla gama de transformações sociais que a partir de 1959 se iniciam em Cuba, [pois] a educação [não só escolar] desempenha um importante papel na estratégia do Estado para lograr uma sólida formação técnico-profissional e ética da população". (LÓPEZ, 2007, p.13). Os primeiros anos após a Revolução foram caracterizados pelos esforços governamentais no sentido de organizar uma nova estrutura educacional, que a partir de 1962 se orientaria "para uma educação, uma escola e uma pedagogia socialista" (RODRÍGUEZ, 2011, p.45).

E se dentro da trajetória para a formação dessa "nova" organização educacional existem marcos históricos que são fundamentais para a sua compreensão (QUINTERO LÓPEZ, 2011, p.55), na década de 60 um desses marcos é a Campanha de Alfabetização, iniciada em 1961. Além dela, outros marcos importantes foram: a Reforma Universitária de 1962; e a criação "do Departamento de Bolsas e a instauração do plano maciço de bolsistas, [que] a partir de 1962, materializaram o direito efetivo ao estudo de todos os cidadãos do país, ao garantir todos os serviços de ensino e de atenção a suas necessidades fundamentais gratuitamente e atendidos pelo Estado" (RODRÍGUEZ, 2011, p.46).

Esses marcos históricos mencionados são produtos dos primeiros anos após a Revolução em Cuba e da nova estrutura educacional proposta pelo novo governo. Este tratará de expandir seu discurso hegemônico em prol da "Revolução", e se esforçará para "unificar" em pés de igualdade as populações urbanas e rurais, assim como para eliminar o analfabetismo (CARNOY, 2009, p.56).

O ponto inicial para implementação desses objetivos desenvolvidos durante a década de 60 - unificação e igualdade das populações urbanas e rurais, eliminação do 
analfabetismo, expansão da autorepresentação do novo governo e seus enunciados ${ }^{2}$ (HORÁCIO, 2016), e expansão educacional-, pode ser observado no processo de realização da Campanha de Alfabetização.

A Campanha de Alfabetização Cubana foi então uma "ação" governamental posta em prática visando à alfabetização, sobretudo de adultas e adultos, respondendo às necessidades da população adulta e utilizando métodos específicos a essa população. Como não havia professoras e professores alfabetizadores suficientes com formação, mas também por outros motivos que serão apresentados ao longo deste texto, estudantes e operários foram mobilizados para, em 1961, agirem na Campanha com o objetivo de erradicar o analfabetismo em Cuba, que nesse momento era de aproximadamente $40 \%$ da população. (GOTT, 2006, p.216).

De acordo com o trabalho da pesquisadora Vera Maria Vidal Peroni, a respeito da Campanha, "seus objetivos e sua própria metodologia estavam profundamente inseridos no processo revolucionário". (PERONI, 2006, p.100). Assim sendo, a respeito da relação entre a construção de um discurso de autorepresentação hegemônico governamental e a Campanha de Alfabetização "a continuidade do processo revolucionário pressupunha a conquista de hegemonia no interior da sociedade cubana. A campanha teve um papel fundamental na consecução dessa hegemonia" (PERONI, 2006, p.100). Segundo a pesquisadora,

Isso ocorreu, por um lado, por meio da formação de "quadros revolucionários", que se incumbiriam de propagar o ideário revolucionário por todo o país e de levar a população a "amar a revolução". Foi o caso, principalmente, dos mestres voluntários, cujo treinamento, ao mesmo tempo em que os preparava para assumir tarefas ligadas à educação, era igualmente treinamento de quadros para a Revolução. São indicadores desse fato tanto os valores perpassados, que chamamos de "currículo oculto", que se expressam via ideias e atitudes de como aprender a viver no coletivo, a prescindir, a incorporar a nova disciplina, bem como as condições materiais do acampamento, que eram quase as mesmas do exército rebelde. (PERONI, 2006, p. 100).

\footnotetext{
2 Para um trabalho sobre "os elementos simbólicos, narrativas e estruturas discursivas que compõem o processo de 'invenção da tradição cubana', e a relação desse processo com as religiões em Cuba", ver: HORACIO, 2016.
} 
Além dos fatores acima mencionados, a pesquisadora chama a atenção para outros aspectos existentes no decorrer da Campanha, que também evidenciaram o seu objetivo, "de busca de hegemonia revolucionária", como o caráter massivo da alfabetização e

Da mesma forma pode se considerar a metodologia utilizada na Campanha. De fato, os temas propostos na cartilha, visando proporcionar ao alfabetizando o estabelecimento de relações entre o seu cotidiano, o momento conjuntural que vivia a sociedade e as mudanças estruturais que estavam ocorrendo, asseguravam-Ihe um melhor entendimento do real, habilitando-o a ter uma participação mais efetiva no processo social. Além disso, ao se referir a questões como a igualdade de direitos para setores discriminados (mulheres e negros), entre muitas outras, a cartilha ainda transmitia o ideário revolucionário e permitia um melhor entendimento do real, objetivando a formação de novos valores adequados ao projeto de uma sociedade mais justa. (PERONI, 2006, p.101).

A respeito do elemento discursivo-hegemônico da Revolução que compunha a Campanha de Alfabetização, vale ressaltar outra face desse processo, ou seja, o aspecto em que "a Campanha era parte da Revolução, as pessoas envolviam-se na Campanha com o intuito de participar da Revolução", tamanha era a força que ela tinha adquirido naquele período histórico em $\mathrm{Cuba}^{3}$. (PERONI, 2006, p.19). Para os estudantes que participaram voluntariamente da Campanha, "a experiência deu a uma geração que não tomara parte da guerra revolucionária o direito de considerar-se parte dela". (GOTT, 2006, p.217).

Tal compreensão do participante da Campanha como "Revolucionário" foi observada inclusive pelo governo, como é possível constatar pelas preparações, treinamentos, e tarefas pelas quais foram submetidos os voluntários da Campanha. Ademais, há elementos que indicam que após a Campanha os voluntários foram "considerados como heróis nacionais e têm nomes em escolas, bandeiras, medalhas de mérito já que passaram por violências de todos os tipos". (MORAIS, 1987, p.57).

\footnotetext{
${ }^{3}$ Um relato à época - de um jovem cubano, inserido no livro de Vera Peroni - pode ilustrar a relação de participação na Campanha como participação na "Revolução": "Motivado fundamentalmente porque quando triunfou a revolução eu tinha 18 anos e estava muito preocupado, pois não havia participado da luta insurrecional. A ditadura foi muito feroz aqui, a tirania, com muitos assassinatos e muita injustiça. Como jovem me sentia complexado por não ter participado da luta clandestina". (PERONI, 2006, p.32).
} 
É importante lembrar que "dezenas de alfabetizadores foram assassinados por "contra-revolucionários", acusados de estarem submetendo o povo à lavagem cerebral vermelha', diz um funcionário do Ministério da Educação". (GOTT, 2006, p. 217). De acordo com o pesquisador Richard Gott, o número de mortos foi superior ao de 40 indivíduos (GOTT, 2006, p.217). A respeito da participação das pessoas na Campanha, para a pesquisadora Vera Peroni:

é conveniente ressaltar que se, por um lado, a Campanha impulsionou a Revolução, ajudando na conquista de hegemonia para o processo revolucionário, por outro lado, é preciso ficar claro que ela não teria sido possível sem a prévia existência desse mesmo processo: participar da Campanha era participar da Revolução, e o clima que envolvia as pessoas motivava-as a essa participação (PERONI, 2006, p.103).

Um dos objetivos anunciados pelo governo cubano, e pela estrutura organizacional da Campanha de Alfabetização, era a construção do "homem novo". Pesquisas indicam "a Campanha de Alfabetização como ponto de partida para a construção do homem novo", que seria - a partir da interpretação dos enunciados produzidos pelos líderes Ernesto Che Guevara e Fidel Castro - "um homem consciente de seu papel de autor e ator da sociedade. Deveria por meio da autoeducação se esforçar ao máximo para se livrar de um passado individualista, assumir uma condição solidária, e uma identidade latino-americana". (ROSA et al, 2021).

A concepção de "homem novo", condição elucidada e sistematizada por Che Guevara em 1965, anos depois da Campanha de Alfabetização, já estava, de algum modo, presente nos processos da Campanha. Essa concepção, segundo a pesquisadora

\footnotetext{
${ }^{4}$ Vale abrir parênteses para apontar, pelo menos, que diferentes autores indicam como os regimes comunistas podem fazer da "sacralização" da política um meio para atender seu objetivo último: a realização de uma revolução antropológica e a regeneração da população para criar um "homem novo" (GENTILE, 2005, p.217). A respeito da estrutura milenarista existentes nos processos como o supracitado, de acordo com Sironneau, "um movimento milenarista pode também fazer emergir, nas representações que o inspiram, inegáveis elementos míticos", pois, segundo Sironneau, "um movimento milenarista é definido pelos seguintes traços: a promessa de uma salvação terrestre e coletiva; promessas e objetivos de caráter ilimitado (outro mundo, outra sociedade, outro tipo de homem); a necessidade de uma ruptura violenta, de uma catástrofe ou de um cataclisma considerado como o decisivo combate que instaurará um mundo transfigurado; uma desproporção máxima entre os fins visados e os meios disponíveis, traço que demarca o milenarismo e a luta política". (SIRONNEAU, 1985, p.263). Para um trabalho que arrole as definições de Religião Política, Religião Civil e Religiões Públicas ver: HORACIO, 2020.
} 
e professora Dayane Rosa, era a de um "homem" preparado "para a consolidação do movimento revolucionário e a construção do socialismo em Cuba apresentava características similares ao homem livre, culto e miliciano propagado como meio de convencimento sobre a importância de se erradicar o analfabetismo do período da Campanha de Alfabetização". (ROSA et al, 2021). Michel Löwy, escrevendo sobre Che Guevara, menciona que para o líder cubano,

a tarefa suprema e última da revolução era criar um homem novo, um homem comunista, negação dialética do indivíduo da sociedade capitalista, transformado em homem-mercadoria alienado, ou capaz de se tornar, graças ao maquinismo imperialista, um animal carniceiro, um "homem-lobo" em uma "sociedade de lobos". (LOWY, 1999, p.42).

A "ideia" do "homem novo" chegou, inclusive, a ser um dos componentes da tensão oriunda das inadequações entre Igreja Católica e o Estado após 1959. Isso porque, a Igreja "não se opõe à revolução primariamente por ela ser contra os interesses da burguesia e do império, mas porque propõe um sistema de valores, uma interpretação da realidade, uma concepção do homem novo e um projeto educativo que são alternativos aos da Igreja"5. (GIRARDI, 1994, p.109). Inclusive, um dos resultados dessa tensão "foi o enfraquecimento institucional da Igreja, que depois sofreria um golpe ainda mais duro com o processo do ateísmo, presente na Constituição de Cuba, iniciado pelo governo cubano, quando este se vincula à União Soviética "6". (HORÁCIO, 2016, p. 153).

A concepção de "homem novo", que provocou divergências com a Igreja Católica, e que fez parte, inclusive, do ideário educacional infantil (BOBES, 2000, p. 262), compreendia um "arquétipo que compendiava as virtudes públicas e as privadas orientado pelo sacrifício, entrega ao trabalho, a austeridade, o envolvimento nos assuntos públicos como dever e o altruísmo". (BOBES, 2000, p.263).

Há pesquisadoras que observam que o Manual Alfabeticemos, utilizado na Campanha de Alfabetização, orientava "a uma práxis pedagógica consciente, que o

\footnotetext{
5 “Além disso, por outra parte, a Revolução Cubana, em resgate do laicismo constitucional, interrompeu objetivamente um processo de reativação religiosa que se verificava ao final da década de 50 e privou a Igreja Católica, a que mais se opôs ao status emergente, de sua posição privilegiada e hegemônica". (CALZADILLA, 2004).

${ }^{6}$ Conforme constou até 1992 na Constituição, Cuba se determinava como um Estado ateu.
} 
convergia no próprio homem novo que seria elucidado de forma mais sistematizada somente em 1965". (ROSA et al, 2021). De modo que, de acordo com as pesquisadoras, se tratando da formação dos alfabetizadores, foi o Manual Alfabeticemos um dos principais instrumentos. Pois,

O Manual Alfabeticemos (CUBA, 1961a) se tornou o veículo pelo qual foi operacionalizado o processo formativo do professor cubano, o manual fez parte de um conjunto de procedimentos pedagógicos e educacionais. Assim, a formação docente revolucionária em Cuba caminhou para uma práxis pedagógica que garantiu o êxito da Campanha de Alfabetização e Cuba tornou-se o primeiro país da América Latina livre do analfabetismo. Essa práxis pedagógica só foi de fato efetiva devido a organização didática dos líderes da Revolução que, por meio do Manual Alfabeticemos (CUBA, 1961a) puderam compartilhar informações e orientações para a formação de uma consciência coletiva. (ROSA et al, 2021).

A respeito do Manual Alfabeticemos, ele era dividido em 3 seções. Uma seção que continha orientações aos professores alfabetizadores voluntários, que incluía apontamentos sobre como usar o Manual, mas, também, referentes ao modo como o alfabetizador deveria se relacionar com os alfabetizandos. Constava no Manual, por exemplo, orientações como:

a) Muéstrese animoso ante las dificultades, piense que trabaja para La Patria combatiendo La ignorância; b) Evite dar órdenes. Diga: Vamos a trabajar. Vamos a estudiar. Use expresiones estimulantes como: i Va muy bien! i Adelante! i Perfecto! etc.; c) Evite el tono autoritario, recuerde que la labor de alfabetización se realiza em común entre alfabetizador y analfabeto; d) Si observa fatiga o cansancio cámbieles de trabajo. (CUBA, 1961, p. 11).

Se na primeira seção da Manual existiam indicações como a supracitada, além da Declaração de Havana, na terceira seção existia, também, um glossário. Já a segunda seção continha 24 temas que orientavam os alfabetizadores para a utilização da cartilha Venceremos!, cartilha que era entregue aos alfabetizandos.

O título da cartilha, Venceremos!, tem relação com as últimas palavras que sempre eram proferidas pelo ex-presidente Fidel Castro nos seus discursos: "Pátria ou Morte! Venceremos!". Na própria contracapa da cartilha havia uma explicação sobre o 
título: "Venceremos! O título responde a firme determinação em que estamos comprometidos. Vencer! Não somente em defesa da nossa Pátria, mas também na Campanha de Alfabetização" (CUBA, 1961, p.02).

A cartilha possuía 15 lições, como a intitulada "A Revolução ganha todas as batalhas", e possuía relação necessária com o Manual do alfabetizador. A capa da cartilha era uma foto que reunia diferentes cubanos aglomerados, como se estivessem vendo um discurso, e uma bandeira de Cuba segurada por uma pessoa. A própria cartilha trazia, na contracapa, a explicação da capa: “Nossa capa, representa o povo em luta por vencer o analfabetismo, dizendo presente: exército rebelde, milícias, camponeses, trabalhadores, profissionais, estudantes, mulheres, crianças, brancos e negros. A bandeira levantada como símbolo de liberdade e união nacional" (CUBA, 1961, p.02).

Ainda a respeito da cartilha, importa destacar as palavras da pesquisadora e professora Dayane Rosa, que realizou importante trabalho de análise da Campanha de Alfabetização, bem como dos manuais e das cartilhas mobilizadas na Campanha. De acordo com a pesquisadora,

As lições da Cartilha Venceremos (1961b) começavam com uma imagem em preto e branco da realidade cubana referente ao tema que seria abordado, era acompanhada de um pequeno texto com frases curtas. As lições, também bem simples como reconhecimento de letras, leitura de palavras, cópia e complete, partiam de uma frase principal do texto e esta frase era decomposta em palavras e depois em sílabas, o que caracterizou o método analítico, denominado de sentenciação, como o recurso metodológico utilizado para a aprendizagem do sistema de escrita alfabética na Campanha de Alfabetização. (ROSA, 2019).

Vale mencionar que além do Manual Alfabeticemos, e da Cartilha Venceremos, outros materiais foram usados como auxiliares, como é o caso da Cartilha ProducirAhorrar-Organizar, e do Manual Cumpliremos!. Sendo que, a Cartilha Producir-AhorrarOrganizar era de aritmética, e seguia o "mesmo padrão da Cartilha Venceremos", com “imagens em preto e branco e exercícios de alfabetização matemática que partiam da realidade do trabalhador rural". (ROSA, 2019). Já o Manual Cumpliremos, foi produzido para complementar o Manual Alfabeticemos, e consta que foi escrito pelo próprio Fidel Castro. Nos seus 7 capítulos o Manual tratava da história de Cuba e da trajetória da 
Revolução, continha "orientações revolucionárias", e servia como material de formação política dos alfabetizadores e alfabetizadoras que trabalhavam na Campanha de Alfabetização.

Sobre os resultados da Campanha, embora aqui neste trabalho tenha sido apontado apenas o aspecto discursivo-hegemônico e organizativo da Campanha, cabe dizer que o êxito da mesma foi reconhecido inclusive pela UNESCO, em 19647, e um dos elementos imprescindíveis da Campanha foi a continuação, através de vários projetos, do processo de Alfabetização de adultos e adultas. Além do que, no fim do ano de início da Campanha, em 1961, o processo obteve “(...) a redução de sua taxa de analfabetismo de $26,3 \%$ aproximadamente para 3,9\%, enquanto em outros países da América Latina, salvo as devidas particularidades, como é o caso do Brasil, a taxa de analfabetismo atingia em média, segundo Pereira (1989), 50,5\% da população ${ }^{8}$. (ROSA, et al, 2021).

Ainda a respeito da importância da Campanha de Alfabetização, vale destacar a "questão da organização da sociedade, dado que o próprio decorrer da Campanha constituiu como um momento de notável estímulo à criação de novas instituições da sociedade civil, bem como ao fortalecimento de instituições já existentes". (PERONI, 2006, p.102).

Além dos benefícios gerados pela Campanha, de acordo com o pesquisador Martin Carnoy, um objetivo importante atingido na década de 60 "foi o acesso universal ao segundo ciclo do ensino fundamental”, além do esforço para nivelar a educação nas áreas urbanas e rurais e as comunidades urbanas. (CARNOY, 2009, p.55).

\footnotetext{
7 Informação retirada do site cubaeduca.cu, em outubro de 2021. Cubaeduca.cu é o portal oficial do Ministério da educação de Cuba. Muitos documentos aqui utilizados foram consultados através desse site.

${ }^{8}$ Segundo Pereira, no “início do ano de 1961, foram localizados 979.207 analfabetos, dos quais 707.000 já estavam alfabetizados em dezembro. Ou seja, durante a Campanha Nacional de Alfabetização ficaram sem alfabetizar-se apenas 272.207 cubanos: 3,9\% da população, pois Cuba tinha então 6.933.253 habitantes. Nesse residual estão excluídos os que se recusaram, os que se alfabetizaram em fevereiro de 1962 e os não-alfabetizáveis por razões de saúde, de idade, e por serem analfabetos em seu idioma, como foi o caso dos 25.000 haitianos residentes nas províncias de Oriente e Camagüey. Não obstante, 3,9\% é um dos índices de analfabetismo mais baixos do mundo, somente comparável com os da União Soviética, Tchecoslováquia, Suíça, França, Inglaterra e Japão. Assim, a experiência cubana no quesito da alfabetização possibilita a problematização de que de fato adotar a aquisição do sistema de escrita alfabética como prática de liberdade seria, segundo Paulo Freire $(1987$, p. 5) “[...] aprender a escrever a sua vida, como autor e como testemunha de sua história, isto é, biografar-se, existenciar-se, historicizarse." (PEREIRA, 1989, p. 18, Apud ROSA, et all, 2021).
} 
Ademais, com relação à educação pré-escolar, surgiu em 1960 a Direção Nacional dos Círculos Infantis, sob a administração econômica do Ministério do Trabalho, que visava pensar procedimentos para a recepção das crianças filhas de mães trabalhadoras. A respeito da educação secundária, na década de 1970 houve, sobretudo com a criação do Departamento Pedagógico Manuel Ascunce Domenech, a implementação das "escolas secundárias básicas (colegial) no campo". Nestas "a ênfase dada ao plano 'à escola ao campo' e outras experiências pedagógicas desenvolvidas na década de 1970 são verdadeiras expressões da política educacional revolucionária" (RODRÍGUEZ, 2011, p.48).

A Campanha de Alfabetização - avaliada e debatida em Cuba, em diferentes momentos, inclusive no I Congresso Nacional de Alfabetização - e seus elementos constituintes, vão ser finalmente aprimorados em 1975 no Primeiro Congresso do Partido Comunista de Cuba, em que se estabeleceu a Tese de Política Educacional, "com sua correspondente Resolução, que oficializava a pedagogia socialista marxistaleninista, sem perder de vista o pensamento educativo martiano e a herança histórica do pensamento educacional cubano de todos os tempos". (RODRÍGUES, 2008, p.48).

Importa mencionar que a Campanha de Alfabetização em Cuba, seus materiais e suas concepções "ultrapassaram os limites do território cubano na década de 1960", tendo, influenciando (ROSA, 2019; CARVALHO, 2015) algumas experiências no Brasil, como a Campanha "De Pé no Chão também se aprende a ler", realizada em Natal. A pesquisadora Dayane Rosa vai mencionar que:

O material didático elaborado para essa campanha em Natal, ficou conhecido como O Livro de Leitura de Pé no Chão. Segundo Góes (1995), esse material se aproximou ao manual Alfabeticemos e a cartilha Venceremos utilizados em Cuba. Para o autor, essa aproximação se deu nos temas contidos no Livro de Leitura de Pé no Chão que discutiam a realidade do alfabetizando, no conteúdo político que pretendia a conscientização do povo e na metodologia (método analítico). (ROSA, 2019, p.22).

\section{A CAMPANHA DE PÉ NO CHÃO TAMBÉM SE APRENDE A LER E PAULO FREIRE}

A Campanha "De Pé no Chão Também se Aprende a Ler" tem seu "nascimento" no ano de 1961, em Natal, influenciada, também, pela Campanha de Alfabetização de 
Cuba (ROSA, 2019; CARVALHO, 2015), e, ainda, atravessada por elementos da "metodologia" freiriana, termo usado por Moacyr de Góes, além de outros fatores que, segundo Moacyr, foram se acrescentando, como:

1) o ensino fundamental até à quarta serie, nos Acampamentos; 2 ) as Praças de Cultura (proposta bebida no MCP); 3) as bibliotecas populares; 4) os círculos de leitura nos Acampamentos; 5) os Círculos de Cultura Paulo Freire; 6) os programas radiofônicos diários; 7) o teatro; 8) o coral; 9) os jograis; 10) as edições de cartilhas para adultos e de literatura de cordel; 11) a mobilização dos grupos de representação de autos populares, cantos e danças folclóricas - eventos integrados, não necessariamente nesta ordem de hierarquia e cronologia. Aqui muito importante foi a Diretoria de Documentação e Cultura dirigida com grande competência por Mailde Pinto. (GÓES, 2002, p.421).

Vale sublinhar que além do contexto supracitado do surgimento das Campanhas e ações na década de 1960, bem como da conjuntura após a Segunda Guerra e durante a Guerra Fria, a Campanha "De Pé no Chão" também se realizou em um momento em que a cidade de Natal tinha 160 mil habitantes, desses "60254 eram analfabetos e estavam fora da escola", sendo que 24444 eram adultos e adultas (GÓES, 2005). A respeito da ocasião do "nascimento" da Campanha "De Pé no Chão Também se Aprende a Ler", o relato do próprio ${ }^{9}$ Moacyr de Góes - que foi coordenador da Campanha, e Secretário de Educação de Natal - é significativo e intenso:

Trabalhávamos, mas a sensação era de darmos "murros" numa grande almofada: a marca do punho ficava impressa no algodão que se esgarçava para as bordas, ou que carregávamos água em peneira. Nesse momento, fui eu convocado pelo Comitê Nacionalista das Rocas, presidido pelo Presbítero José Fernandes Machado, para discutir, justamente, a erradicação do analfabetismo naquele Bairro. Levei para a reunião dois dados: a estatística do crescimento de Escolinhas nas Rocas e a notícia de que não havia dinheiro para construir a tão sonhada rede de escolas municipais. Longa foi à discussão e sincera a cobrança de compromissos da campanha eleitoral de Djalma Maranhão. Em meio à discussão, um participante pede a palavra a propõe: se não pode construir escolas de alvenaria faça escolas cobertas de palha de coqueiro, mas faça a escola. De todas as discussões políticas que

\footnotetext{
${ }^{9}$ Este trabalho optou por construir uma breve ordem de apresentação da Campanha de "Pé no Chão também se aprender a ler", a partir de "falas" e escritos do próprio coordenador da Campanha, Moacyr de Góes, através de algumas entrevistas e palestras realizadas por Moacyr de Góes, e artigos e livro escritos por ele. Inclusive, por isso, muitas serão as citações do próprio coordenador.
} 
participei na minha vida e não foram poucas esta foi uma oportunidade inesquecível pela criatividade da proposta e novas sugestões de desdobramentos. No final, na melhor tradição democrática, a proposta foi votada e aprovada pelo Comitê Nacionalista das Rocas. No mesmo dia levei a decisão ao Prefeito. Ele aprovou a ideia. E dois dias depois, com os marceneiros da Prefeitura, José Ribamar à frente, e a ajuda dos pescadores do Canto do Mangue, começou a ser erguido o primeiro Acampamento Escolar. Em fevereiro de 1961, de microfone à mão, acompanhado do Grupo de Trabalho de Educação Popular da SME, caminhando pelas areias das Rocas, Djalma Maranhão convocava o povo das Rocas para a matrícula nos Acampamentos Escolares. Estava nas ruas a luta pela erradicação do analfabetismo em Natal que, pouco depois, veio se chamar Campanha "De Pé no Chão Também se Aprende a Ler." (ARAÚJO, 2015, p.246).

Conforme pode ser lido na citação acima, a Campanha “De Pés no Chão também se aprender a ler" vai ser possível e vai ser articulada a partir dos movimentos populares, os Comitês Nacionalistas ou Comitês de Rua. Eram 240 comitês organizados em Natal, isso em 1960, com calendários de convenções dos comitês, por bairros. Dos comitês saíam "as listagens dos problemas-soluções”. (GÓES, 2005). Moacyr de Góes menciona que em setembro de 1960 delegações do interior do Rio Grande do Norte, e mais de 200 comitês, participaram da I Convenção Estadual do Movimento Nacionalista. Da Convenção emergiu uma relação de prioridades, e a primeira delas era justamente a erradicação do analfabetismo, que se tornou compromisso, inclusive constando no programa de governo, do depois prefeito Djalma Maranhão.

A partir daí, com Moacyr de Góes já Secretário de Educação, no mandato de Djalma Maranhão, criou-se o Grupo de Trabalho de Educação Popular, para, também, dialogar com os comitês nacionalistas e pensar a questão da erradicação do analfabetismo. Nesse movimento, em 1961, há a realização do curso de treinamento para monitores, que habilitou, aproximadamente, 200 pessoas. Ainda em 1961, desenvolve-se o I Seminário de Estudos dos Problemas de Educação e Cultura do município de Natal, visando, entre outras ações, a erradicação do analfabetismo, tendo participado decisivamente desse processo Margarida de Jesus Cortez.

Também em 1961 Moacyr de Góes é convocado pelo Comitê Nacionalista das Rocas, conforme o relato acima, e em 1962 - um ano depois da experiência no MCP, e um ano antes de Angicos - se realiza uma etapa de experimentação do "método" do educador Paulo Freire, "nos treinamentos dos 'animadores - alfabetizadores' para os 
círculos de cultura". (GÓES, 2005). Nesse momento já está em gestação a Campanha “De Pé no Chão", pois de 1960 até 1962 ela se realiza com a "metodologia tradicional aplicada em cursos noturnos", e no final de 1962 o "Método de Alfabetização de 40 horas de Paulo Freire é aplicado em 12 Círculos de Cultura, localizados nas Rocas e nas Quintas" (GÓES, 2005), e em 1963, e início de 1964, já se desenvolve a “Metodologia do Livro de Leitura de Adultos De Pé no Chão produzido pela SME coordenado por Maria Diva da Salete Lucena e inspirado por livro semelhante editado pelo MCP, de autoria de Josina de Maria Lopes Godoy e Norma Porto Carreira Coelho". (GÓES, 2005).

\section{A METODOLOGIA E A CARTILHA}

Inicialmente se destaca, segundo o próprio Moacyr de Góes, que "na interiorização de Pé no Chão as três metodologias foram aplicadas, dependendo da realidade local". (GÓES, 2005). Isso significa que, a possibilidade aberta pela Metodologia e Cartilha foram complementadas ou alternadas, de acordo com o local em que experiência foi desenvolvida. Portanto, segundo Moacyr de Góes, também no “De Pé no Chão" a "Educação Popular adota, principalmente, duas ferramentas de trabalho: o Método Paulo Freire e sua função conscientizadora e a cartilha de alfabetização e sua função politizadora. Ambos remetendo à educação de adulto". (GÓES, 2002).

$\mathrm{Na}$ primeira possibilidade, aquela da metodologia freiriana, a "pedagogia da pergunta", o Círculo de Cultura, a "palavra pesquisada em seu universo vocabular" e existencial, são alguns dos elementos centrais, e, de acordo com Moacyr de Góes, a Campanha "De Pés no Chão" é uma das experiências que faz parte "da cronologia dos experimentos do Sistema Paulo Freire". Sendo que, segundo Moacyr de Góes, "a metodologia do Sistema Paulo Freire implica o cumprimento das conhecidas etapas que devem ser executadas na seguinte ordem:"

levantamento do universo vocabular do grupo que se vai alfabetizar; seleção neste universo dos vocábulos geradores sob um duplo critério: o da riqueza fonêmica e o da pluralidade de engajamento na realidade local, regional e nacional; criação de situações existenciais, típicas do grupo que se vai alfabetizar; criação de fichas-roteiro, que auxiliam os coordenadores de 
debate no trabalho; feitura de fichas com a decomposição das famílias fonêmicas correspondentes aos vocábulos geradores. (GÓES, 1991).

Já a segunda possibilidade, aquela da "cartilha politizadora", é, conforme Moacyr de Góes, uma busca de sintonia da "Educação Popular brasileira com a Revolução Cubana que, no momento, empreendia a sua libertação do analfabetismo, erradicandoo da Ilha". (GÓES, 2002). Isso porque, como já fora mencionado, a "Campanha de Dé no Chão também se Aprender a Ler" adaptou indiretamente - ao adaptar a cartilha da MCP, que por sua vez se inspirou na experiência cubana - a Cartilha Cubana às condições de Natal, "em texto recriado pela SME sob a coordenação de Maria Diva da Salete Lucena". (GÓES, 2002).

Portanto, o "Livro de leitura de pé no chão também se aprende a ler" ficou conhecido como Cartilha de Alfabetização de adultos, que foi editada em 1963, e teve como organizadora a professora Maria Diva da Salete Lucena. Moacyr de Góes menciona que "não é uma proposta original, e sim adaptação do Livro de leitura para adultos do MCP, do Recife". Moacyr de Góes destaca que,

À época, o MCP se apresentava, na área de educação de adultos, com duas propostas que internamente conflitavam: a metodologia do Sistema Paulo Freire, que utilizava projetores e slides, e a metodologia de Norma Porto Carreiro Coelho e Josina Maria Lopes de Godoy, centrada numa cartilha compatível com o universo cultural do adulto analfabeto. Ambas as propostas partiam da conscientização do educando, do despertar de sua consciência crítica, buscando um processo global de politização. Assim, as duas propostas interessavam à Campanha, que as empregou nas classes de adultos. Diria que fizemos uma síntese das duas posições. Em face dos obstáculos para o emprego ortodoxo do Sistema Paulo Freire, terminamos utilizando a escrita de Coelho/ Godoy e a oralidade de Freire. Isto é: partindo da lição da Cartilha, era aberta toda a discussão com a linguagem conscientizadora de Paulo Freire, nas classes de adultos, nos Círculos de Pais e Professores, nas Praças de Cultura, nos teatros, na imprensa, nos textos legais, no discurso político - enfim, em todas as manifestações culturais da Campanha, excetuando a escola primária de crianças e de adolescentes. (GÓES, 1991, p. 113).

Importa mencionar ainda que a utilização da Cartilha exigiu "qualificações" especiais, nos Cursos de Emergência, para aqueles e aquelas que trabalhariam com ela. Foi inserido então um novo módulo nos Cursos de Emergência, "de formação de 
professores", novo módulo denominado de Curso de Realidade Brasileira, permitindo nele, conversas, debates e aprendizados sobre conteúdos e possibilidades de aplicação da Cartilha. Assim,

Para os futuros regentes de classes, que ministrarão cursos para adultos, surgem temas que até então o CFP da Campanha não trabalhara, como Processo espoliativo do imperialismo, Cultura brasileira e alienação, Cultura popular, Análise crítica da Constituição brasileira, Realidade brasileira Reformas de base, Aspectos da economia brasileira, O professor primário em face da realidade brasileira - Análise da cartilha. (GÓES, 1991, p.156).

Moacyr de Góes menciona, nas diferentes conversas e palestras sobre a Campanha e sobre a Cartilha, que não só a Campanha foi interrompida pela Ditadura Militar no Brasil, mas a Cartilha foi utilizada pelos militares como local de "busca de mensagens subversivas aos alfabetizandos adultos da Campanha", tendo como consequências dessa ação dos militares muitas prisões e demissões, tristemente, até o fim da Campanha, que coincidiu com a prisão e o exílio de muitas envolvidas e muitos envolvidos, como do próprio Moacyr de Góes, do prefeito Djalma Maranhão e do educador Paulo Freire ${ }^{10}$.

\footnotetext{
${ }^{10}$ Não posso deixar de trazer a triste fala de Moacyr de Góes sobre as violências da Ditadura: "Em abril e maio de 1964, todo o staff da educação municipal caiu. Dispersos pela deposição e prisão do Prefeito em 02 de abril, reencontrei os meus companheiros de trabalho nas prisões do 160 RI, do 70 RO e da Polícia Militar do Estado: Omar Fernandes Pimenta (diretor de Ensino), Mailde Ferreira de Almeida (diretora da Documentação e Cultura), Margarida de Jesus Cortez (diretora do Centro de Formação de Professores), Geniberto Paiva Campos (diretor do Colégio Municipal de Natal), Maria Diva da Salete Lucena (vicediretora do CFP), Francisco Floripe Ginani (chefe de Gabinete da Secretaria Municipal de Educação), Josemá Azevedo (responsável pela interiorização da Campanha), José Fernandes Machado (presidente do Comitê Nacionalista das Rocas e responsável pelo Sistema Paulo Freire na Cooperativa dos Pescadores do Canto do Mangue), João Faustino Ferreira Neto (presidente da União Estadual dos Estudantes e professor do CFP De Pé no Chão). Outras lideranças que, assistematicamente, colaboraram com a Campanha também estavam presas ou foragidas: Luís Gonzaga dos Santos (vice-prefeito), Luís Ignácio Maranhão Filho (ex-deputado estadual), Aldo da Fonseca Tinoso (suplente de deputado federal), Hélio Xavier de Vasconcelos (presidente do CCP), Pretextato José da Cruz e Evlim Medeiros (do Comando Estadual dos Trabalhadores), Carlos Alberto de Lima (da Folha da Tarde) e mais as seguintes lideranças universitárias que eventualmente participavam da Campanha: Maria Laly Carneiro, Tereza de Brito Braga, Berenice de Medeiros Freitas, Danilo Lopes Bessa, Nei Leandro de Castro, José Arruda Filho, Paulo Frassinete de Oliveira, Guaracy Queiroz de Oliveira e Eurico Reis. Marcos José de Castro Guerra, que liderou a experiência de Angicos, quando aplicou o Sistema Paulo Freire, no âmbito do Governo do Estado, foi preso por oito vezes, sucessivamente, entre abril e dezembro de 1964. A professora Maria Conceição Pinto de Góes, minha mulher, vice-diretora do Colégio Municipal e organizadora de dezenas de Comitês Nacionalistas, grávida do quinto filho, esteve sob ameaças e provocações dos órgãos de repressão durante todo o período de minha prisão, isto é, por mais de seis meses. Solto por força de habeas-corpus em 25 de novembro de 1964187, demitido de todos os empregos, sem condições de sobrevivência
} 


\section{CONSIDERAÇÕES FINAIS}

No entanto, importa destacar que, se o Golpe Civil-Militar de 1964 e a Ditadura Militar interromperam o pleno desenvolvimento da Campanha "De Pés no Chão também se aprende a ler", Moacyr de Góes aponta, em um tipo de análise "numa perspectiva histórica de 40 anos $^{11 "}$ ", que a campanha "venceu quatro desafios comuns à escola brasileira", quais foram: "Não confundiu escola com prédio escolar; 2- Qualificou seus próprios recursos humanos e municipalizou o ensino normal de formação de professores". Além do que, a Campanha "produziu seus próprios textos educativos, face à alienação das cartilhas então existentes no mercado", e nela a "sala de aula não foi largada à própria sorte: o acompanhamento técnicopedagógico se fez na proporção de um supervisor para vinte professores." (GÓES, 2005).

Mais do que tudo isso, Moacyr de Góes destaca que do ano de 1961 até o ano de 1963 a Campanha percorreu uma importante trajetória, em que "de uma escola que se limitara inicialmente a reproduzir, culturalmente, o sistema, passara a ser uma escola que buscava um modelo próprio de sistema; de uma escola que pretendia "levar a cultura (a verdade) ao povo", evoluía para uma postura de troca de saberes com o povo" (GÓES, 2005), uma campanha que estava "aprendendo com o povo" justamente no momento em foi interrompida violenta e precocemente.

Outrossim, Moacyr de Góes menciona que em um estudo realizado por ele comparando as três cartilhas, a da Revolução Cubana, a do MCP do Recife e a de "De Pé no Chão" - obteve como resultado a constatação da atualidade desses textos pedagógicos, em que Moacyr de Góes ficou a "refletir que nós, no Recife e em Natal, seguíamos o caminho certo para a erradicação de analfabetismo pois estávamos afinados com a única experiência que deu certo para superação do analfabetismo nas Américas, até hoje", se referindo ele à experiência cubana, mas fazendo uma importante ressalva: "a diferença é que na Ilha ocorria o processo de uma Revolução

deixamos a cidade no dia seguinte. Alguns meses depois os filhos seguiram o mesmo caminho". (GÓES, 1991).

${ }^{11}$ No livro De Pés no Chão também se aprender a ler, há um capítulo em que Moacyr de Góes realiza "uma visão retrospectiva 15 anos depois". (GÓES, 1991). 
Socialista e, no Nordeste brasileiro, nosso horizonte foi um golpe de estado de direita. (...)". (GÓES, 2002).

Além do que, entre os importantes desdobramentos da Campanha, Moacyr de Góes, em entrevista dada antes do seu falecimento em 2008, mencionou que em Timor Leste um grupo que estava "(re)construindo o sistema de educação daquele bravo povo", acabou por escolher o "De Pé no Chão Também se Aprender a Ler", por melhor se adequar a realidade pós-guerra do Timor Leste, sendo que Moacyr de Góes destacou, ao observar essa escolha, que é "bom saber que a proposta educacional de nossa Cidade do Natal não foi destruída pelo Golpe de 1964, pois, 40 anos depois, ela ressurge num estado do Oriente de língua portuguesa". (ARAÚJO, 2015).

Moacyr de Góes dizia que compartilhava essa notícia supracitada "sem triunfalismo, mas confortado pela História", e, também nesse ponto, concordo com ele, até porque, nós todes que lutamos por justiça social não esperamos resignadamente derrotados que a História "faça acertos de conta ou se vingue do passado", mas levamos à sério a compreensão de que os dignos e legítimos projetos podem até ser interrompidos, mas nunca são extintos e eliminados, porque se o nosso tempo é o tempo da justiça, da ancestralidade, da exemplaridade, das memórias - e suas narrativas - tempo da resistência; nosso espaço é o dos territórios ancestrais - que, inclusive, não se limitam a espacialidade "geofísica" - dos terreiros, do coletivo, da comunhão sem fronteiras, tanto que a Campanha de Natal não se restringiu ao Nordeste, e a campanha de Alfabetização Cubana não se restringiu a Cuba, até porque, como mencionou Maria Elizete Carvalho "com efeito, a sintonia da educação popular no Nordeste dos anos 60 com a campanha de erradicação do analfabetismo em Cuba aponta, também, para uma conexão no sentido político-ideológico de deter a trajetória da dominação ${ }^{12 " \prime}$. (2015).

Ademais, há a sobrevivência intensa da perspectiva da Educação Popular, não só porque "Paulo Freire, no exílio e depois dele, continuou a escrever, criando uma escola, discutindo e aprofundando os postulados de sua proposta educacional" (GÓES, 2002), mas, sobretudo porque, e nisso também concordo com Moacyr de Góes, "entramos no

\footnotetext{
12 “Por trás desse novo discurso da Campanha, está a influência da Revolução Cubana, que se exerceu em todos os movimentos progressistas da época. Uma consulta aos jornais de então e, no caso especifico de Natal, à Folha da Tarde, de propriedade de Djalma Maranhão, constatará a grande repercussão, no Brasil, da revolução fidelista". (CARVALHO, 2015; Apud GÓES, 1991, p. 119).
} 
Século 21 e os professores continuam a refletir e experimentar a partir de parâmetros que se encontram na obra de Freire. 1964 já é um passado distante [tristemente nem tão distante e tampouco resolvido] mas o presente e o futuro continuarão a fazer descobertas a partir do pensamento do educador pernambucano". (2002). Que assim seja, sigamos!!!

\section{REFERÊNCIAS BIBLIOGRÁFICAS}

ARAÚJO, Marta Maria de. Campanha de Pé no Chão Também se Aprende a Ler. Entrevista com Moacyr de Góes. Revista Educação em Questão, Natal, v. 53, n. 39, p. 242-254, set./dez. 2015.

BOBES, Velia Cecilia. Los Laberintos de la Imaginación: repertorio simbólico, identidades y actores del cambio social em Cuba. México: El colégio de México, 2000.

CARNOY, Martin; GOVE, Amber K.; MARSHALL, Jeffery H. A vantagem acadêmica de Cuba.Trad. Carlos Szlak. São Paulo: Ediouro, 2009.

CARVALHO, Maria Elizete Guimarães. O livro de leitura de pé no chão: 1963 (uma cartilha democrática). Anais do IV Seminário Nacional HISTEDBR - Grupo de Estudos e Pesquisas História, Sociedade e Educação no Brasil, 2015.

CUBA, Ministerio de la Educación. Alfabeticemos manual para el Alfabetizador. La Habana: Imprenta Nacional, 1961a.

CUBA, Ministério de la Educación. Venceremos. La Habana: Imprenta Nacional, 1961b.

GÓES, Moacyr de. De pé no chão também se aprende a ler: 1961 - 64: uma escola democrática. 2. ed. São Paulo: Cortez, 1991.

GÓES, Moacyr de. Cuba - Recife - Natal: ou o sonho de três cartilhas de alfabetização par mudar o mundo. Contexto \& Educação. Revista de Educación en América y el Caribe. p.45 - 64, jul/set. 1995.

GÓES, Moacyr de. Educação Popular, campanha de Pé no Chão também se aprender a ler, Paulo Freire \& Movimentos Sociais contemporâneos. In: ROSAS, Paulo (org.). Paulo Freire, Educação e Transformação Social. Recife: Editora Universitária, UFPE, Centro Paulo Freire de Estudos e Pesquisas, 2002.

GÓES, Moacyr de. Natal anos 60: De Pé no chão também se aprender a ler \& Círculo de Cultura. Educação de Jovens e Adultos, vol. 1. Natal, 2005.

GENTILE, Emilio. Les religions de la politique : entre démocraties et totalitarismes. France: Éditions du Seuil, 2005.

GOTT, Richard. Cuba, uma nova história. Rio de Janeiro: Jorge Zahar Editor, 2006. 
HORÁCIO, Heiberle H. Fundamentalismo e Religião da Política: uma possibilidade da política como religião. Horizonte: Revista de Estudos de Teologia e Ciências da Religião, v.18, p.1002 - 1030, 2020.

HORÁCIO, Heiberle H. Apontamentos sobre a (in)existência de elementos religiosos na tradição inventada cubana: subsídios para reflexões sobre uma eventual dimensão religiosa pública. Ciencias Sociales y Religión. , v.v.18, p.150-171 - 150, 2016.

HORÁCIO, Heiberle H. Formação Docente, Pensamentos Indígena, De(s)colonial e Filosofias Africanas na disciplina Filosofia do Cursinho Popular Darcy Ribeiro In: Formação Docente: Experiências metodológicas, tecnológicas e práticas.1 ed.Ponta Grossa-PR: Atena Editora, 2021, p. 17-27.

LÓPEZ, M. Q. A educação em Cuba: seus fundamentos e desafios. Estudos Avançados, v. 25, n. 72, p. 55-72, 2011

LÖWY, Michel. O pensamento de Che Guevara. São Paulo: Expressão Popular, 1999.

MONTERO, Pilar Rico (org.). El modelo de la escuela primaria cubana: uma propuesta desanrrolladora de educación, enseñansa y aprendizaje. Editorial Pueblo $Y$ Educación, 2008.

MORAIS, Fernando. A Ilha: um repórter brasileiro no país de Fidel Castro. São Paulo: Ed. Alfa-Omega, 1980.

PEREIRA, Manuel. Rebeldes sem armas: alfabetizadores cubanos em ação. São Paulo: Editora Ática, 1989.

PERONI, Vera Maria Vidal. A campanha de alfabetização em Cuba. Porto Alegre: Editora UFRGS, 2006.

QUINTERO LÓPEZ, Margarita. A educação em Cuba: seus fundamentos e desafios. In: Revista de Estudos Avançados-USP, 25 (72), 2011.

RODRÍGUEZ, Justo Alberto Chávez. A educação em Cuba entre 1959 e 2010. In: Revista de Estudos Avançados-USP, 25 (72) 2011.

ROSA, Dayane de Freitas Colombo. Cuba e a formação docente revolucionária: a construção do homem novo. Dissertação (mestrado) - Universidade Estadual de Maringá, Centro de Ciências Humanas, Letras e Artes, Programa de Pós-graduação em Educação, 2019.

ROSA, Dayane. de F. C.; AMARAL, R. G. do; MELO, J. J. P. A construção do homem novo em Cuba (1959- 1961): um processo de transformação por meio da alfabetização como prática de liberdade. Revista HISTEDBR, Campinas, SP, v. 21, p. 1- 21, 2021.

SIRONNEAU, Jean-Pierre. Sécularisation et religions politiques. Paris: La Haye, 1982.

SIRONNEAU, Jean-Pierre. Retorno do mito e imaginário sócio-político e organizacional. Revista da Faculdade de Educação, São Paulo, v. 11, n.1-2, p. 243-273, 1985. 